\section{Orale Quaddelprophylaxe}

\begin{abstract}
S oforttypreaktionen nach Mückenstichen entwickeln sich meist in der Kindheit und werden durch spezifische IgE-Antikörper gegen Bestandteile des Mückenspeichels vermittelt. Der Großteil der sensibilisierten Personen reagiert sowohl mit einer sofortigen Quaddelbildung als auch mit verzögert auftretenden Papeln, jeweils begleitet von starkem Juckreiz. In nördlichen Ländern wie Finnland nehmen manche Betroffene während der gesamten Mückensaison orale Antihistaminika ein. In einem plazebokontrollierten Doppelblindversuch erwies sich nun die Einnahme von $5 \mathrm{mg}$ Levocetirizin als gut wirksam gegen den Juckreiz und die Größenausdehnung der
\end{abstract}

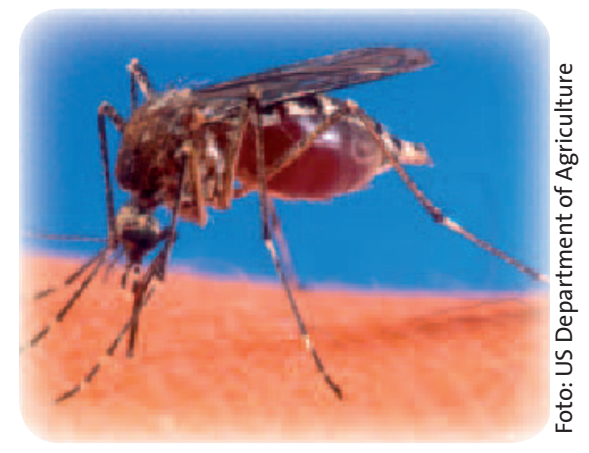

Effloreszenzen nach einer Stichprovokation durch Labormücken der Art Aedes aegypti. Besonders profitierten die Patienten, bei denen außergewöhnlich große Quaddeln auftraten.

\section{$b k$}

Karppinen A et al. Acta Derm Venereol 2006; 86: 329-31

\title{
Frauenherzen in Gefahr
}

D icke Luft erhöht das Risiko für kardiovaskuläre Ereignisse - zumindest bei Frauen. Epidemiologen dokumentierten beginnend in den Jahren 1994 bis 1998 im Schnitt sechs Jahre lang die Daten von 65.893 postmenopausalen Frauen im US-Bundesstaat Washington. Es erlitten 1.816 Probandinnen ein kardiovaskuläres Ereignis. Der Grad der Feinstaubbelastung am Wohnort zeigte sich dabei als unabhängiger Risikofaktor. Jede $\mathrm{Zu}$ nahme der Belastung um $10 \mu \mathrm{g} / \mathrm{m}^{3}$ ging mit einer 24\%igen Erhöhung des Risikos einher.

\section{Miller KA et al. N Engl J Med 2007; 356:} 447-58

\section{Pflege mit Zusatzeffekt}

W enn sich Raucher oder Exraucher regelmäßig einer Computertomografie (CT) unterziehen, werden zwar mehr Lungenkrebsfälle diagnostiziert, die Zahl der Todesfälle sinkt jedoch nicht. US-Onkologen führten über einen Zeitraum von im Mittel 4,9 Jahren hinweg bei 3.246 beschwerdefreien Probanden jährlich eine Lungen-CT durch. Dabei diagnostizierten sie 144 Lungenkrebsfälle - fast dreimal so viele wie ohne Screening entdeckt worden wären. Trotzdem gab es in der Folgezeit 38 Todesfälle, was fast exakt dem Wert entspricht, der auch ohne Screening statistisch zu erwarten gewesen wäre.

de

Bach PB et al. JAMA 2007; 297: 953-61

\section{Kreuzreaktive Pilze}

chimmelpilzsporen - beispielsweise
von Cladosporium herbarum oder $\mathrm{Al}$ ternaria alternata - können allergische Rhinitis und allergisches Asthma auslösen. Bei der Diagnostik werden Tests verwendet, die spezifisches IgE gegen Pilze im Serum nachweisen. Die Ergebnisse sollten aber vor allem bei Patienten mit atopischer Dermatitis mit Vorsicht interpretiert werden: Bei diesen Patienten sind häufig spezifische IgE-Antikörper auch gegen Hefen (Malassezia spp.) nachweisbar, welche die Haut besiedeln. Ein Teil dieser
Malassezia-positiven Atopiker zeigt Kreuzreaktionen gegen Schimmelpilze, die Untersuchung auf Schimmelpilz-spezifisches IgE ergibt also möglicherweise falsch positive Ergebnisse. Der Grund für die Kreuzreaktivität ist auch schon gefunden: Es handelt sich um relativ große, bisher allerdings noch nicht näher charakterisierte Mannan-haltige Glykoproteine, die sowohl bei Schimmel- als auch Hefepilzen vorkommen. $\quad b k$

Leino $M$ et al. Int Arch Allergy Immunol 2006; 140: 30-5

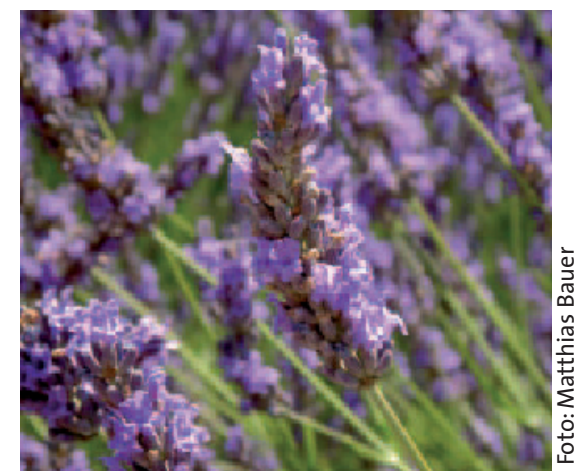

— ine Gynäkomastie bei Jungen vor der Pubertät ist bei 90\% der Fälle idiopathisch. Anhand von drei Fallbeispielen meinen US-Pädiater nun einen möglichen Auslöser für eine Vergrößerung der männlichen Brustdüse festgestellt zu haben: Kosmetikprodukte, die Lavendel- oder Teebaumöl enthalten. Drei Jungen im Alter zwischen vier und zehn Jahren hatten einen „Heilbalsam“, Shampoo und Haargel oder Seife und Körperlotion mit Lavendel- und Teebaumöl verwendet. In allen drei Fällen wurde dazu geraten, die offenbar östrogen wirkenden Produkte abzusetzen. Mit Erfolg: Die Gynäkomastien bildeten sich im Laufe einiger Monate vollständig zurück.

$n z$

Henley DV et al. N Engl J Med 2007; 356: 479-85 